\title{
Ingestion of a Denture Cleanser: Did It Cause Gastric Perforation?
}

\author{
Daniel M. Ingram, MD, MSPHa, George M. Bosse, MD ${ }^{a, b}$, Richard Baldwin, PhDc
}

aDepartment of Emergency Medicine, University of Louisville, Louisville, KY

bKentucky Regional Poison Center, Louisville, KY

cDepartment of Chemistry, University of Louisville, Louisville, KY

\begin{abstract}
Introduction: Human ingestion of denture cleansers leading to gastric perforation has not previously been described.

Case Report: A 27-year-old male ingested three denture cleanser tablets in water over two days in an attempt to cause a falsenegative result on a workplace urine drug screen. Seven days later he presented to an emergency department with a perforated gas-

Discussion: A literature review of cases and the chemistry of the components of his ingestion was conducted to determine the possible relationship between these events. Ingestion of intact fragments of the tablets would be likely to result in significant gastric toxicity, but ingestion of dissolved tablets would be unlikely to have caused his illness.
\end{abstract} tric ulcer.

\section{INTRODUCTION}

Efferdent is a product designed to cleanse dentures in a container when added to water. The outside of the package clearly states in large, highlighted, capitalized letters: "Do not put tablets or solution directly in mouth." Despite this warning and similar ones found on other denture cleansing products, there were 1,512 reported exposures to denture cleanser products by the Toxic Exposure Surveillance System in 2005. Of these, 77\% were in adults over 19 years old. Only 38 (2.5\%) were intentional, 97.5\% were accidental, $82(5.4 \%)$ were treated in a healthcare facility, 8 $(0.5 \%)$ were found to cause "moderate" complications, and only one resulted in death, though no further information is reported about this case [1].

\section{CASE REPORT}

A 27-year-old man presented to an Emergency Department (ED) complaining of severe abdominal pain, diarrhea, and blood-tinged vomitus. Ten days prior the patient had been offered a job interview that required pre-employment urine drug testing. Because he had been smoking marijuana regularly, he followed a friend's suggestion to attempt manipulation of the cannabinoid assay through ingestion of Efferdent tablets. Seven days prior to presentation he ingested one tablet in a glass of water, which quickly resulted in abdominal pain. The following day he ingested two more tablets in water, which resulted in abdominal pain that continued to increase until presentation. He did not comment on whether the tablets were fully dissolved.

The patient had no significant past medical or surgical history, took no medications, and had no allergies to medications. His family history was non-contributory. He denied any prior gastrointestinal symptoms. His social history was positive for tobacco abuse and negative for alcohol use.

The patient's vital signs were: oral temperature, $36.1^{\circ} \mathrm{C}$, heart rate $62 \mathrm{bpm}$, respiratory rate 18/minute, blood pressure 150/78 $\mathrm{mmHg}$, and $\mathrm{O}_{2}$ saturation $98 \%$ on room air. On physical examination, he was a thin male in moderate distress secondary to

Keywords: denture cleanser, ingestion, toxicity, gastric perforation Notes: There was no outside funding of any kind used for this study. Corresponding Author: George M. Bosse, c/o Kentucky Regional Poison Control Center, PO Box 35070, Louisville, KY 40232-5070. Phone: 502589-8222 Email: bosseg@insightbb.com 


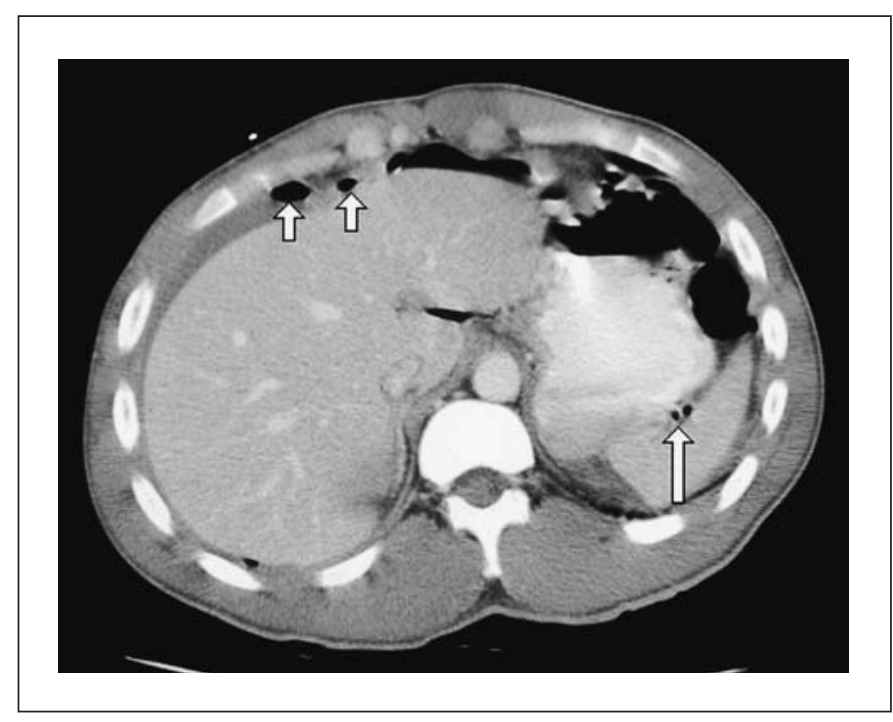

Figure 1: CT scan of abdomen illustrating free air and fluid

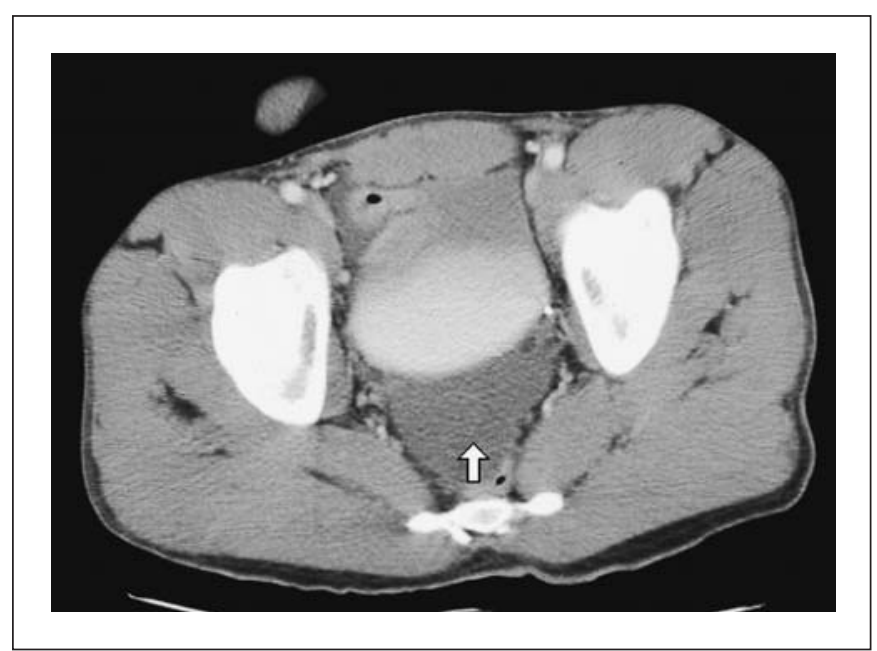

Figure 2: CT scan of pelvis illustrating free air

abdominal pain that was exacerbated in the sitting position. His abdominal examination revealed diminished bowel sounds, and marked epigastric tenderness with rigidity and involuntary guarding. He was also vomiting small amounts of blood-tinged emesis. Consultation with the local poison control center revealed that the ingested product contained sodium perborate monohydrate.

An abdominal series showed a non-obstructive bowel gas pattern and no free air. Computed tomography (CT) of the abdomen and pelvis was obtained, which demonstrated extensive free fluid and free air (Figures 1 and 2). Surgical consultation was obtained.

Exploratory laparotomy revealed a 0.5 -cm gastric ulcer with perforation and $1 \mathrm{~L}$ of pus within the peritoneal cavity. Irrigation, debridement and Heineke-Mikulicz pyloroplasty were successful. The patient recovered without further complications.

\section{DISCUSSION}

We report a case of a gastric perforation after ingestion of a denture cleanser. Review of the medical literature finds only a few cases of ingestion of denture cleansing agents with significant effects and no cases of gastric perforation. Studies in which Denalan, Efferdent, Polident and the Canadian denture cleanser Ansodent were deposited undiluted directly into the esophagus of dogs resulted in extensive local soft tissue necrosis and coagulation necrosis in the stomach and esophagus as demonstrated on necropsy $[2,3]$. Another study that placed denture cleansing powders in the oral cavity and esophagus of sedated dogs produced similar results [4]. Finally, a case report that discusses two elderly patients who unintentionally ingested denture cleansing tablets containing sodium perborate and trisodium phosphate were found to have esophageal strictures on esophagoscopy [5].

Pfizer, the manufacturer of Efferdent, lists the ingredients in alphabetical order: Blue \#2, ethylenediaminetetraacetic acid (EDTA), FDNC Green \#3, flavor, polytetrafloroethylene (Teflon, DuPont), potassium monopersulfate, sodium bicarbonate, sodium lauryl sulfoacetate, sodium perborate monohydrate, sodium saccharine, sodium sulfate, and sodium tripolyphosphate anhydrous. The product has a $\mathrm{pH}$ of 9.5 , weighs $2.1 \mathrm{~g} /$ tablet, and has a titratable $\mathrm{O}_{2}$ of $129-162 \mathrm{mg} /$ tablet (personal communication with Pfizer Products Hotline, 2005). The Material Safety Data Sheet (MSDS) for Efferdent states that it is $48 \%$ sodium perborate monohydrate, $21 \%$ potassium monopersulfate, 20\% EDTA, and $11 \%$ "non-regulated/non-hazardous ingredients" [6].

The patient ingested a total of $6.3 \mathrm{~g}$ of Efferdent over two days, containing $3.0 \mathrm{~g}$ of sodium perborate monohydrate, $1.3 \mathrm{~g}$ of potassium monopersulfate, and $1.25 \mathrm{~g}$ of EDTA. While sodium tripolyphosphate anhydrous, sodium lauryl sulfoacetate, and sodium sulfate are possible mucous membrane irritants, none would be expected to have any significant tissue toxicity in this small quantity $[7,8]$. EDTA can cause tetany secondary to calcium chelation if injected in sufficient quantities, but this would not be expected with the small quantities ingested in this case [8].

The primary "active ingredient" in Efferdent is sodium perborate monohydrate $\left(\mathrm{BO}_{3} \mathrm{Na} \bullet \mathrm{H}_{2} \mathrm{O}\right)$. It is one of two commonly used alkaline oxidizing agents in denture cleansers. The other commonly used agent is carbamide peroxide [9]. Sodium perborate monohydrate is an irritant. When added to water, it dissociates to form approximately $36 \%$ hydrogen peroxide [9] and $64 \%$ sodium borate by weight [8]. The toxicities of ingested hydrogen peroxide and borate salts are considered separately.

Ingestion of hydrogen peroxide may result in local tissue toxicity and air emboli [10]. Although hydrogen peroxide toxicity is possible following ingestion of a 3\% household strength solution, it becomes more likely as concentrations increase to those of industrial strength ( $\geq 35 \%)$. Bloody emesis and multiple ulcers of the gastric antrum were found in one case of a previously healthy 3-year-old child who ingested $180 \mathrm{~mL}$ of 3\% hydrogen peroxide [11].

A 2.1-g tablet of Efferdent dissolved in $250 \mathrm{~mL}$ of water should yield a solution of $0.174 \%$ hydrogen peroxide, which is 
approximately $1 / 17$ as concentrated as household hydrogen peroxide [12]. Ingestion of $750 \mathrm{~mL}$ of a solution this dilute over two days would not be expected to cause gastric perforation in an adult. However, intact tablet fragments of significant size could be expected to cause marked local tissue toxicity, as demonstrated by the dog studies noted above [2-4].

Boric acid and related borate salts are thought to have approximately equivalent toxicity. They have been reported to produce numerous toxic effects, including nausea, vomiting, gastric irritation, rashes, and central nervous system, renal and hepatic toxicity. Gastric and dermatologic effects may appear regardless of the mechanism of exposure [13].

One Efferdent tablet contains the equivalent of $0.65 \mathrm{~g}$ of sodium borate, which dissolved in $250 \mathrm{~mL}$ of water would produce a solution of approximately $0.26 \%$. It is difficult to obtain reliable estimates on minimal toxic or lethal single, oral doses of boric acid or borate salts from the literature [14]. Estimates of potentially toxic and lethal doses vary widely. At the extremes, there is a case in which death resulted from a 3-g ingestion in a 2-week-old infant and a report of $88.8 \mathrm{~g}$ ingested by one woman that seemed to have little obvious effect [14-16].

Opinions on the toxicity of boric acid and its salts have changed markedly over the last century [16]. Early in the $20^{\text {th }}$ century, boric acid and its salts were included in many healthcare products, including baby powders, contraceptive jellies, and antiseptics [13, 17-19]. Concerns about toxicity that arose in the middle of the 20th century caused its use to decline rapidly. An article from 1953 reviewing 109 cases, mostly chronic exposures, revealed a mortality from boric acid ingestion of $55 \%[20]$.

A more recent article from 1988 reviewed 784 cases of acute boric acid ingestion in which toxicity was minimal or absent [16]. The quantity of borate reported to have been ingested ranged from $10 \mathrm{mg}$ to $88.8 \mathrm{~g}$ in the 692 asymptomatic patients (mean $0.9 \mathrm{~g}$ ) and $100 \mathrm{mg}$ to $55.5 \mathrm{~g}$ in the remaining symptomatic patients (mean $3.2 \mathrm{~g}$ ). None experienced serious toxicity, though four were dialyzed. It seems unlikely that an adult ingesting $3 \mathrm{~g}$ of sodium perborate monohydrate over two days would develop gastric perforation due to its borate component $[19,21,22]$.

Given that both the amount of borate and concentration of hydrogen peroxide ingestions would not generally be expected to cause toxicity in an adult, possible explanations for the patient's perforated gastric include ingestion of intact tablet fragments and exacerbation of a preexisting but undiagnosed peptic ulcer or pure coincidence.

There is a body of literature on adulterating samples or ingesting substances to produce false negative results on employmentrelated urine drug screens. However, most methods relate either to adding an adulterant to the urine sample after voiding or ingesting a diuretic or herbal preparation to dilute the urine. A literature review of ingestion of oxidants or denture cleansers for this purpose failed to find any studies or comments on the topic. Presumably this is not a common method, as it appears to not have been previously described.

\section{CONCLUSION}

A 27-year-old male ingested three denture cleanser tablets in water over a two-day period in an attempt to cause a false negative result on a pre-employment urine drug screen. Seven days later he presented to an ED with a perforated gastric ulcer, which was successfully repaired. Literature review and chemical analysis of this product reveal that it is unlikely to cause gastric perforation unless undissolved fragments were ingested. As this patient has no history to suggest a previous peptic ulcer, it is possible that his perforation was related to the ingestion.

The authors have no potential financial conflicts of interest to report.

\section{REFERENCES}

1. Lai MW, Klein-Schwartz W, Rodgers GC, Abrams JY, Haber DA, Bronstein AC, Wruk KM. 2005 Annual Report of the American Association of Poison Control Centers Toxic Exposure Surveillance System. Clin Tox 2006;44:803-932.

2. Abramson AL. Corrosive injury of the esophagus, result of ingesting some denture cleanser tablets and powder. Arch Otolaryngol 1978; 104:514-516.

3. Abramson AL, Eason RM, Pryor WH, Messer EJ. Upper digestive tract burns caused by Denalan ${ }^{\circledR}$ denture cleanser powder. Ann Otol 1975;84:102-106.

4. Abramson AL, Eason RL, Pryor WH, Messer EJ. Corrosive injury of the oral cavity and esophagus caused by some denture cleanser powders. Ann Otol 1974;83:714-719.

5. Patrick AW, Cameron EWJ, Ford MJ. Oesophageal stricture following inadvertent ingestion of Steradent tablets in the elderly. Scott Med J 1986;31:181.

6. Material Safety Data Sheet for Efferdent Denture Cleaner. Warner Lambert Co. 1996.

7. Budavari S, O’Neil MG, Smith A, Heckleman PE, Kinneary JF, editors. The Merck Index, An Encyclopedia of Chemicals, Drugs and Biologicals. 12th ed. Whitehouse Station, NJ: Merck \& Co., Inc. 1996.

8. Gosselin RE, Smith R, Hodge HC. Clinical Toxicology of Commercial Products. 5th ed. Baltimore: Williams \& Wilkins; 1984.

9. Dahl JE, Pallesen U. Tooth bleaching-a critical review of the biological aspects. Crit Rev Oral Biol Med 2003;14(4):

292-304.

10. Watt BE, Proudfoot AT, Vale JA. Hydrogen peroxide poisoning. Toxicol Rev 2004;23(1):51-57.

11. Henry MC, Wheeler J, Mofenson HC, Caraccio TR, Marsh M, Comer GM, et al. Hydrogen peroxide 3\% exposures. Clin Tox 1996;34(3):323-327.

12. Cotton FA, Wilkinson G. Advanced Inorganic Chemistry. 5th ed. New York: John Wiley \& Sons; 1988.

13. Ross CA, Conway JF. The dangers of boric acid: its use as an irrigant and report of a case. American Journal of Surgery 1943;60(3):386-395. 
14. Brooke C, Boggs T. Boric-acid poisoning, a report of a case and a review of the literature. AMA Am J Dis Child

1951;82:465-472.

15. Valdez-Dapena MA, Arey JB. Boric acid poisoning: three fatal cases with pancreatic inclusions and a review of the literature. J Pediatr 1962;61(4):531-546.

16. Litovitz TL, Klein-Schwartz W, Oderda GM, Schmitz BF. Clinical manifestations of toxicity in a series of 784 boric acid ingestions. AJEM 1988;6(3):209-213.

17. Rust CA, McNally WD. The distribution of boric acid in human organs in six deaths due to boric acid poisoning. JAMA 1928;90(5):382-383.
18. Boric acid: benign or malignant? Pfizer Spectrum 1957;5(19):558-559.

19. Ishii Y, Fujizuka N, Takahashi T, Shimizu K, Tuchida A, Yano S, et al. A fatal case of acute boric acid poisoning. Clin Tox 1993;31(2):345-352.

20. Goldbloom RB, Goldbloom A. Boric acid poisoning, report of four cases and a review of 109 cases from the world literature. J Pediatr 1953;43(6):631-643.

21. Restuccio A, Mortensen ME, Kelly MT. Fatal ingestion of boric acid in an adult. AJEM 1992;10(6):545-547.

22. Linden $\mathrm{CH}$, Hall $\mathrm{AH}$, Kulig KW, Rumack BH. Acute ingestions of boric acid. Clin Tox 1986;24(4):269-279. 